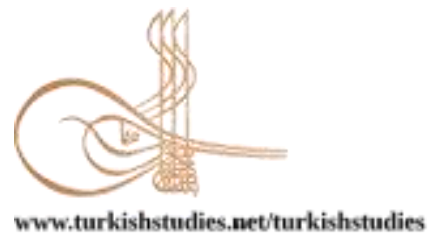

Turkish Studies

eISSN: $1308-2140$

Research Article / Araștırma Makalesi

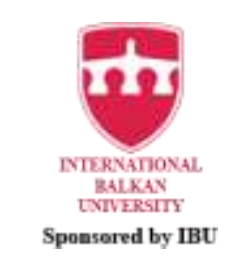

\title{
Batı Hristiyan Kültür ve Sanatına Karşı Bir Antitez: İslam Estetiğinin Meta Kritiği
}

An Antithesis up Against Western Christian Culture and Art: The Metacritics of Islam Aesthetic

\author{
Emir Hasan Ülger*
}

\begin{abstract}
This review aims to make an episteme-ontological evaluation on Islamic aesthetics. Islamic aesthetics is the most common name of the intellectual consensus that determines the instruments, methods and limits of the artistic production system, which has emerged structurally similar in many different cultures within the Islamic culture. The basic principle to bear in mind when conducting a review on Islamic aesthetics is to surmount Islamic aesthetics in its unique ontology and epistemology. In this sense, there is a need for a radical change in thought. It would be wrong to attempt to evaluate Islamic aesthetics with the concepts and tradition of Western aesthetics since Islamic art initially positioned itself as a culture against Western art and culture. This review scrutinizes the ontological origin of the Islamic aesthetic tradition, the view of the concept of sensitivity, the idea of creating an aesthetized world, the idea of the existence of beautiful things to be added to human life by humans themselves, the general conceptual framework of the aesthetic experience directed from the material world to the abstract to grasp the conceptual reality of the beauty. One of the most common mistakes in Islamic aesthetics is related to the "prohibition of images and perspective". The constructive powers of art in Islamic aesthetics do not reveal a rational and holistic system that progresses universally in history like Western art, on the contrary, Islamic art wants to reveal the truth of the minor, particular art works. The existence and the revelation of the truth of these particular works of art also require a hermeneutic and phenomenological but also existential analytics. In this review, a critical analysis was sought to be made against the traditional theses on Islamic aesthetics. For this purpose, the general boundaries of Islamic aesthetics, their development and the episteme-ontological background of their aesthetic moves were intended to be discussed.
\end{abstract}

Structured Abstract: This review aims to make an episteme-ontological evaluation on Islamic aesthetics. Islamic aesthetics is the most common name of the intellectual consensus that determines the instruments, methods and limits of the artistic production system, which has emerged structurally similar in many different cultures within the Islamic culture. The basic principle to bear in mind when conducting a review on Islamic aesthetics is to surmount Islamic aesthetics in its unique ontology and epistemology. In this sense, there is a need for a radical change in thought. It would be wrong to attempt to evaluate Islamic aesthetics with the concepts and tradition of Western aesthetics since Islamic art initially positioned itself as a culture against Western art and culture.

This review scrutinizes the ontological origin of the Islamic aesthetic tradition, the view of the concept of sensitivity, the idea of creating an aesthetized world, the idea of the existence of beautiful things

\footnotetext{
* Doç.Dr., Başkent Üniversitesi, Güzel Sanatlar, Tasarım ve Mimarlık Fakültesi Assoc. Prof. Dr., Başkent University Faculty of Fine Arts, Design and Architecture ORCID 0000000227445443

emirhulger@gmail.com

Cite as/ Atıf: Ülger, E. H. (2021). Batı Hristiyan kültür ve sanatına karşı bir antitez: İslam estetiğinin meta kritiği. Turkish Studies, 16(1), 389-408. https://dx.doi.org/10.7827/TurkishStudies.47384

Received/Geliş: 05 November/Kasım 2020

Accepted/Kabul: 20 Şubat/February 2021

Checked by plagiarism software

Published/Yayın: 25 Şubat/February 2021

CC BY-NC 4.0
} 
to be added to human life by humans themselves, the general conceptual framework of the aesthetic experience directed from the material world to the abstract to grasp the conceptual reality of the beauty. One of the most common mistakes in Islamic aesthetics is related to the "prohibition of images and perspective". The constructive powers of art in Islamic aesthetics do not reveal a rational and holistic system that progresses universally in history like Western art, on the contrary, Islamic art wants to reveal the truth of the minor, particular art works. The existence and the revelation of the truth of these particular works of art also require a hermeneutic and phenomenological but also existential analytics.

Islamic art initially gravitated not towards the material aspect of existence, but to the ideal aspect. The works of art do not appear as universal truth, but as art forms in which the particular aspects of the "One" are indirectly reflected. At this point, the power that reveals the work does not matter much because that person actually plays an intermediary role. Therefore, the artist does not appear before us as a "subject" model. In addition, the constructive powers of art in Islamic aesthetics impose the ban on "images" to prevent dependence on the phenomenal world against the dangers posed by Christian paganism and the pre-Islamic idol of Arabs, and also to enrich the artist's imagination. Islamic art thus transitions to a more imaginative and geometric plane. Islamic art is also distant to the dialectic that has evolved and transcends itself towards a certain goal. In parallel with all these, different production techniques and expertise have developed from the Western artistic forms in "spatial, visual and auditory" arts. This process in fact gives us clues about the process of the formation of a new culture.

It might not be possible see a "classical" or "modern" period, a temporal point of excellence in which Islamic aesthetics can historically be traced. The attitude of Islamic aesthetics is extremely disparate and important against the claims of "universality, rationality, creation and progress" or the "grand narratives" existing in the Western intellectual tradition. The basic idea to be understood in respect to Islamic art is that it is not a super-structural institution shaped and manipulated deliberately by a certain political union or the Arabs, Turks and Iranians. It should, on the contrary, be understood that this art is concerned with all the thoughts and creations of religious and worldly life that emerge in the process of creating artistic works basically compatible with Islamic concepts, but developed with the effect of different centers and cultures and even geographies.

In Islamic aesthetics, it is seen that the most fundamental and strong debate is focused on the ontological origin and epistemological position of the artwork in terms of "art ontology" as far as the "act of artistic creation' is concerned. The most important discussion focused on the dialectical relationship between "liberty-necessity and creativity" in terms of Islamic aesthetics. The effect of the meta-criticism of these two concepts at a theoretical point can be observed in the dialectic of idealism and worldliness of many particular works of art. It might also be seen that this theoretical effect does not constitute an art production system and paradigm integrated with a super-structural determination. It might therefore be very difficult in Islamic aesthetics to trace an entity abstracted from the historical and spatial plane of a holistic aesthetic understanding, doctrine and aesthetic tradition, theoretical and practical particular examples as in the West. One of the main reasons for this is undoubtedly the non-existence of a doctrinal structure similar to church organization as the main source of authority in the field of 'thought and aesthetics' in the Islamic tradition.

Following these evaluations, this research opens to discussion "the general principles of aesthetics", independent of the initially "aesthetic and particular" and subsequently "epistemological and ontological" creation of works of art of the aesthetic paradigm formed with reference to the general framework of Islamic aesthetics. As a result of the analysis based on the relationship between concepts, the constructive principles of Islamic aesthetics are intended to be explained in relation to the productive processes of aesthetics, by focusing directly on the aesthetics itself. This review might thus serve the purpose of opening a new horizon in the discussions of Islamic aesthetics with the possibility of making a possible "meta-criticism" that focuses directly on the constructive principles of Islamic aesthetics and the constitutive of this aesthetic.

In this review, a critical analysis was sought to be made against the traditional theses on Islamic aesthetics. For this purpose, the general boundaries of Islamic aesthetics, their development and the epistemeontological background of their aesthetic moves were intended to be discussed.

Keywords: Philosophy, aesthetics, Islamic aesthetics, ontology of art, meta critic 
Öz: Bu incelemede İslam estetiği üzerine episteme-ontolojik bir değerlendirme yapılmak istenmiştir. İslam estetiği, İslam kültürü içinde birbirinden farklı pek çok kültürde yapısal olarak benzer şekilde ortaya çıkan sanatsal üretim sisteminin hem araç ve yöntemini hem de sınırlarını tayin eden düşünsel uzlaşının en genel adı olmaktadır. İslam estetiği üzerine bir inceleme yaparken akılda tutulması gereken temel ilke, İslam estetiğini kendine özgü ontoloji ve epistemoloji içinde ele almaktır. Bu noktada düşüncede radikal bir değişime ihtiyaç vardır. Batı estetiğinin kendi içinden çıkan kavramlarıyla ve geleneğiyle İslam estetiğini değerlendirmeye çalışmak hatalı olacaktır çünkü İslam sanatı daha başlangıçta kendisini batı sanat ve kültürüne karşıt bir kültür olarak konumlandırmış̧ır. Bu incelemede İslam estetik geleneğinin ontolojik kökeni, duyarlılık kavramına bakış, estetize edilmiş bir dünya yaratma fikri, insan yaşamına insan eliyle katılacak güzel şeylerin varlığı düşüncesi, güzelin kavramsal gerçekliğinin kavranabilmesi için maddesel dünyadan soyut olana yönelen estetik tecrübenin genel kavramsal çerçevesi irdelenmiştir. İslam estetiği üzerine bilinen en yaygın hatalardan birisi de "suret yasağı ve perspektif" ile ilgilidir. İslam estetiğinde sanatın yapıcı güçleri, batı sanatı gibi tarih içinde evrensel olarak ilerleyen, rasyonel ve bütünlüklü bir sistem ortaya çıkartmaz; aksine İslam sanatı, minör olanı, tikel sanat yapıtlarının hakikatini açığa çıartmak ister. Bu tikel sanat yapıtlarının varlığı ve hakikatinin açığa çıkartılması da ancak hermeneutik ve fenomenolojik ama aynı zamanda varoluşsal bir analitiği gerektirmektedir. Bu incelemede İslam estetiği üzerine var olan geleneksel tezlere karşı eleştirel bir analiz yapılmak istenmiştir. Bu amaçla İslam estetiğinin genel sınırları, gelişimi ve estetik hamlelerinin episteme-ontolojik arka planı tartışmaya açılmak istenmiş̧ir.

Anahtar Kelimeler: Felsefe, estetik, İslam estetiği, sanat ontolojisi, meta kritik.

\section{Giriş}

Düşünce tarihinde İslam estetiği hakkında pek çok tartışma bulunmaktadır. $\mathrm{Bu}$ tartışmaların genelinde terminoloji belirli bir paradigma içinde kaldığı için İslam estetiğinin nesnel bir analizinin yapılabilmesi güçleşmektedir. Bu konuda bütünlüklü bir incelemenin dilimizde felsefi olarak yapılmadığı da açıktır.

İslam estetiği kuşkusuz İslamiyet'in kurucusunun düşüncelerinden bağımsız değildir. Arapça, "tarz, yol" anlamına gelen "sünnet", İslam geleneğinde Hz. Muhammed'in farz olarak tanımlanan, Kur'an'ın emirleri dışındaki davranışları ve herhangi bir konuda söylemiş olduğuna inanılan "söz, fiil ya da takrirlerine" verilen addır. İslam kültürü temelde, Kur'an-1 Kerim ve Hazreti Muhammed'in düşünce ve davranışlarıyla örnek alınmaya değen eylemleriyle şekillenir. Aklın kılavuzluğunu her zaman yücelten Kur'an ve Hz. Muhammed'in yolu, rasyonalite-bilim ve sanatın da yoludur ve bu yolda müminlere düş̧en görev de bu yolu akıl ve irade birliğiyle takip etmektir. Bu noktada İslam estetiği, tıpkı İslam felsefesi gibi, İslam dininin paradigmalarıyla belirlenmiştir. Tıpkı İslam kültürü gibi İslam estetiği de başlangıçta kendisini "Budistik-Yahudi ve Hıristiyan" dinsel estetizasyon ve kültürüne karşı "karşıt bir kültür" olarak şekillendirmiştir. Bu amaçla kendisinden önceki hiçbir uygarlığın belirlenim, etki ve gölgesinde kalmayıp kendi felsefi temelleriyle özgürce yeni bir otantik kültür oluşturmayı istemiştir. Bu noktada çelişkinin varlığını korumak amacıyla İslam düşüncesi, batı kültür ve sanatına karşıt bir antitez olarak, "kültür ve sanatını", "karşıt bir kültür” olarak konumlandırmıştır.

İslam estetiği üzerine yapılan inceleme ve değerlendirmelerin genelinde yapılan yaygın bir hata, ölçüt olarak batı sanatının alınmasıdır. Grek, Romen veya geç Rönesans sanatlarının incelemesinde kullanılan estetik kriterler ${ }^{l}$ Islam sanatının incelenmesinde geçerli değildir. (Bahnassi, 2008:63) İslam sanatı, kendi gelişim seyri içinde ve özellikle İslam felsefesinin temel paradigmalarıla koşut düşünüldügünde ancak anlaşılabilecek bir sanatı ifade eder. İslam estetiği üzerine düşündügümüzde Platon ve Aristoteles'e kadar giden ontolojik tartışmanın 1şı̆̆ında gerçekleşen yaratıcı, yaratma ve yaratılan ilişkisi ve bununla ilişkili olarak ortaya çıkan dikatomik ayrım öncelikli olarak fark edilir. Ayrıca İslam sanatında, yaratıcı düşünce, formalist estetiğin

\footnotetext{
${ }^{1}$ Batı sanatının toplumsal analizinde Rönesans döneminde yaşadığı temel değişimlerle ilgili ayrıntılı tartışma için bakınız, A. Hauser, Sanatın Toplumsal Tarihi, Saray Sanatının Çöküşü, s. 3-31
} 
sınırlarını daha başlangıçta zorlar. Bu noktada Yunan-Çin ve Amerikan sanatlarından farklıdır: Yunan, Roma insan vücudunun anatomik mükemmeliyetine sayg prensibine dayanır. Hint ve Çin sanatlar ahlaki idealleri sembolik tasvirlerde anlatmaya çalışmış, Aztekler, Kolomb öncesi sanatları insan suretin tanrların suretinin aracılığlyla ifade etmiştir. (Bahnassi, 2008:631) Oysa İslam estetiği, bu uygarlıklarda açığa çıkan sanatsal ilkelerden farklı olarak "kendinde ve kendisi için" bir estetik doktrin oluşturmuştur. Bunu, mimetik sanat teorisinin temsil sanatı uygulamasına karşı hamlesinde daha net görürüz. Bu düzeyde İslam medeniyetinin sanatı, anlatının olmadığ ikonsuz bir sanattır. (Leaman, 2012:39) Böyle olunca İslam sanat1, zorunlu olarak temsili olmayan soyut sanat formlarına yönelir.

İslam estetiğinde batı sanatı ve düşüncesindeki gibi tarih içinde, evrensel olarak ilerleyen, rasyonel ve bütünlüklü bir sanat eserler sistemi de ortaya çıkartmaz. Islam sanatı, minör olanı, tikel sanat yapıtlarını görünüre çıkartmak ister. (Leaman, 2012:47) İslam estetiği daha başlangıçta varlığın görünen yüzüne (maddesel) değil görünmeyen yüzüne (ideal-soyut) yoğunlaşır. Yani sanat yapıtlarının evrensel ve tümel bir kavramsallaştırılmış, tarih ve zaman içinde olgunlaşan, "bütünlüklü bir varlığı" düşüncesi, ilkesel olarak daha başlangıçta yadsınmıştır. Böyle olunca İslam estetiği üzerine geliştirilecek herhangi bir düşüncenin zorunlu olarak fenomenolojik ve hermeneutik bir metodolojiyle ilerlemesi zorunluluğu açığa çıkar. Çünkü İslam estetiği, sözünü ettiğimiz gerekçeler ve metodolojik olarak, tarih üstü ele alınmak durumundadır. Böyle olunca Hegel karşıtı bir tikel sanat yapısı (sistemi diyemiyoruz) ve oluşumunu İslam estetiğinde görürüz. ${ }^{2}$ Bütünlük, tarihsellik ve diyalektik evrim bu estetik tecrübenin içinde var olmaz. İslam estetiği bu noktada Hegel karşıtıdır, çünkü bu estetikte sanat tarihsel olarak ilerleyen, bütünlüklü ve rasyonel bir yapının bilinçlenme sürecinin ara bir halkası değildir. İslam estetiğinin paradigması daha çok Adorno, Heidegger, Strauss, Gadamer, Derrrida ve Eco'nun dile getirdiklerine yakın gelişme göstermiştir. (Hamdouni Muhammed, 2015:5) İslam sanat,, "özerk, tikel, yaşantısal ve tecrübe temelinde" gelişen, "dil öncesi bir yeti" olarak değil fakat "dil ötesi bir evre" olarak, kendisini batı düşünsel geleneğinin çok geç dile getirdiği kavramsal perspektifle oluşturmuştur. ${ }^{3}$ Böylece, zorunlu olarak İslam estetiğinin tikel ürünlerini, "tarih ve dilin" dışında, "fenomenolojik ve hermeneutik" bir metodolojiyle tecrübe edilmesi zorunluluğu açığa çıkmaktadır. Bu yüzden evrensel-sanatsal üretim ilkeleri, dönemi ve tarzı gibi düşünceler gelişmemiş; aksine kendi içinde "minör, yaşamsal ve tikel" olanın hakikatini ön plana çıkartmak isteyen bir gelişme kendisini zorunlu olarak göstermiştir.

İslam estetiğinin izinin sürüleceği zamansal bir mükemmellik noktası olan "klasik" ya da "modern" bir dönem göremeyiz. Batı düşünce geleneğinde var olan "evrensellik, rasyonalite, yaratma ve ilerleme" iddiaları ya da büyük anlatılarına karşı İslam estetiğinin karşıt tavrı son derece önemlidir. İslam sanatı, denildiğinde anlaşılması gereken temel şey, bu sanatın sadece Arap, Türk ve İranlının ya da belli bir siyasal birliğin, bilinçli bir şekilde yönlendirdiği ve toplumu buna göre şekillendirdiği üst yapısal bir kurum değil fakat daha farklı merkez ve kültürlerin hatta coğrafyaların etkisiyle gelişen ama temelde İslami kavramlarla uyumlu sanatsal eser yaratma sürecinde ortaya çıkan bütün dini ve dünyevi yaşama dönük düşünce ve yaratıları anlamamız gerekir. Çünkü İslam medeniyeti, Müslüman olan etnik gruplarl ve dil gruplarını aştı̆̆ından, etniler üstü bir medeniyettir. (Leaman, 2012:39)

İslam estetiğinde, "sanatsal yaratma" eylemi üzerine düşündüğümüzde en temel tartışma konusunun, sanat ontolojisi açısından sanat eserinin ontolojik kökeni ve epistemolojik konumu üzerine olduğunu görürüz. İslam estetiği açısından en derin tartışma konusunun hürriyet-zorunluluk

\footnotetext{
${ }^{2}$ Hegel estetik kuramı üzerine ayrıntılı tartışma için bakınız, G. W. F. Hegel, Estetik, Sanat Güzelliği İdeası veya İdeal, s.91-104 \& İdealin Dışsal Belirlenimi, s. 243-262

${ }^{3}$ Ayrıntılı tartışma için bakınız, Bernstein J.M. (1992) The Fate of Art, Aesthetic Alienation from Kant to Derrida and Adorno
} 
ve yaratıcılık arasındaki diyalektik ilişki üzerine odaklandığını görürüz. Bu iki kavramın meta kritiğinin kuramsal bir noktada yaratmış olduğu etkiyi pek çok tikel sanat yapıtının fenomenolojik ve hermeneutik analizinde görürüz. Bu kuramsal etkinin üst yapısal bir belirlenimle bütünlüklü bir sanat üretim sistemi ve paradigması oluşturmadığını da görürüz. İslam estetiğinde, batıdaki gibi bütünlüklü bir estetik kavrayış, doktrin ve estetik geleneğini, kuramsal ve uygulamalı tikel örneklerinin tarihsel ve mekânsal düzlemden soyutlanmış bir varlı̆̆ın izini sürmek bu yüzden oldukça zordur. Bunun temel nedenlerinden birisi de "düşün ve estetik" alanında var olan temel otorite kaynağı olan kilise örgütlenmesine benzer bir doktriner yapının İslam geleneğinde var olmamasıyla ilişkilidir. Böyle olunca İslam kültür ve sanatı kaçınılmaz olarak tarihsel ve mekânsal olarak düz bir çizgide gelişim seyri göstermeyip farklı coğrafyalarda çeşitliliğe sahip olmaktadır: İslam kültürünün geçmişteki kaynakları Bizans uygarlığının kaynaklarını andırıyordu ama geri kalanı için Müslümanlar, Arabistan, Mezopotamya, Iran ve Hindistan'ın eski kültürlerinden çok daha fazlasını ödünç aldılar. (Artz, 1980:125) Böylece, "çok uluslu, çok kültürlü” bir coğrafyaya yayılan bu medeniyet, tek bir merkezden yönetilen estetik bir doktrinle değil, fakat çok merkezli, farklı perspektifleri içeren tikel sanat yapıtlarının varlığını barındıran, kolektif bir üretim yaklaşımı olarak karşımıza çıkmaktadır. İslam kültürü ve sanatı denildiğinde pek çok farklı ulustan oluşan Araplar, İranlılar, Türkler, Berberiler, Hintliler, Mağriplilerden oluşan bir coğrafyadan bahsederiz. İslam sanatında Musevi, Hristiyan Kıpti ve İran etkisi açıktır. İslam estetiği ya da sanatı denildiğinde Arap yarımadası, Ön Asya, İran, Afganistan, Türkistan, Kuzey ve Orta Afrika halklarının geliştirdiği sanatlar anlaşılmaktadır. İslam sanatının erken dönemi, klasik dönemi ve geç dönemi, kendi içinde düşünüldüğünde farklı İslam ülkelerinde farklı zamanlarda ve farklı öncelliklerle ortaya çıkmıştır. Bu yüzden İslam estetiği denildiğinde zorunlu olarak her dönemi Sünni, Arap, Fars, Kuzey Afrika, Endülüs, Hint, Türk kendi içinde düşünmemiz ve değerlendirmemiz daha doğru olacaktır.

İslam sanatı hakkında literatürde pek çok yanlış anlaşılma vardır. Bunlar pek çok başlıkta siralanabilir. Oliver Leaman İslam Estetiğine Giriş adlı eserinin birinci bölümünde İslam estetiği hakkında en çok yinelenen bir hata başlığını taşımaktadır. Bu yanlış anlaşılmalar kuşkusuz İslam sanatının, batı sanatı ilkeleriyle değerlendirmesinden kaynağını almaktadır. Batı merkezcil akılbilim ve düşünce kavramının pozitivist perspektifinin sarsılması, "yapısal ve postmodern" değişimle, rasyonalite, ilerleme, yaratıcı özne, "sanatın ölümü" gibi merkezi kavramlar artık önemini kaybetmiştir. (Hamdouni: 2015:4-5) Buna bağlı olarak artık batı merkezli kavramlarla İslam estetiğinin tikel ürünlerinin incelemesi ve değerlendirilmesi yanılgısından uzaklaşmak gerekmektedir. Yapısal Antropoloji'de Strauss'un değerlendirmelerinden hareketle batı merkezcil bir optik perspektifin evrensel olarak var olmadığını da görürüz. (Strauss, 2012:350-351) Aslında bu bakış, belli bir kültürel pedagoji içinde epistemolojik olarak oluşmakta ve "dışarıda kalanı" görmemizi engelleyen bir baskı aygıtına dönüşmektedir. Bu sanatsal ve baskıcı akıl, aynı zamanda ötekileştiren ve başka türlü bir oluşuma izin vermeyen dominant bir tahakküm aracıdır aynı zamanda. İlkel sanatında var olan, yandan bakış ve perspektif gelişiminin, mantıksal düzeni ve uzamsal arka planın derinliği noktasındaki gelişimi, batı sanatının perspektifsel gelişimiyle boy ölçüşecek düzeydeyken 8.yy.'dan 13.yy.'a kadar olağanüstü bir düşün ve sanatsal gelişme gösteren İslam düşüncesinin perspektiften yoksun olduğunu düşünmek ve eleştirileri bu noktaya odaklanmak, batı merkezcil yanılgılarla dolu bakışın bir tezahürüdür aslında. Gerçekte, İslam estetiğinin üretim süreci pratiklerinde pek çok eserde ve dönemde perspektif bulunur. Fakat genel olarak perspektife karşı olunmasının temel nedeni sanatçının bakışının alımlayıcıya zorla dayatılmasına karşı olunması düşüncesine dayanmaktadır. Bu düşünce, son derece modern bir sanatsal özgürleşme modelinin yıllar önce uygulamasıdır aslında. Leaman'ın "yanlış anlaşılma" 
dediği şey, aslında tek başına bir yanlış anlaşılma değil fakat daha bilinçli üretilen siyasi bir düşüncenin Said'in değimiyle “kültü̈r emperyalizmi”nin ${ }^{4}$ tezahüründen başka bir şey değildir.

Bu incelemede İslam estetik düşüncesi ve ontolojisinin temel dayanaklarına bağlı olarak tikel sanat türleri ve sanat kuramlarının ve sistemlerinin ötesinde, doğrudan, İslam estetiğinin kendisini oluşturan ilkelerin yapısal bir analiz yapılmak istenmiştir.

\section{Platon- Bir Yanlış Anlaşılma mı? Temsil Yasağı ve Neden Oldukları}

İslam sanatı temelde idealist bir ontolojiye dayanır. Bunun temel dayanağını İslam felsefesinin idealist Platoncu ve Yeni Platoncu etkisinde görürüz. İslam sanat felsefesinde yaratıc1 zihin, maddesel, gelip geçici, "zahiri" olana değil "görünüşün" ardındaki, "batini" olana yönelir. $\mathrm{Bu}$ tartışma konusunun temeli Platon'a kadar gider. Platon'a göre sanatçı, eseri yoktan var etmez; $\mathrm{O}$, ancak zamansal ve mekânsal olarak sonlu tikel bir nesnenin, yeni bir sanatsal imgeyle üçüncü dereceden ancak bir taklit ürünü olarak yaratabilir. İnsan aklı ve duyarlılı̆̆ının sınırları, verilen gerçeklik alanının duyarlılık çerçevesinde belirlenmiştir. İslam estetiği açısından düşündüğümüzde hem İslam metafiziği hem de Platon'un etkisiyle sanatçı ve onun üretimi yeni ve orijinal bir üretimi içermemektedir. Benzetmeci (sanatçı,) benzettiği şeylerin aslını ne kendi bilir ne de başkalarından ögrenir. Benzetmeci, benzettiği şeylerin ne olduğunu pek bilmez; yaptığ iş, ciddi insanlara yaklşmayan bir oyundur. (Platon, 2005: 6012-b) Platon'un ontoloji temelli bu düşünceleri Gazali'nin fikirlerinde kendisine daha geniş bir yer bulacaktır. Gazali'ye göre Göz görür, ama asıl mesele nesnelerin ya da görünüşün ardını anlayacak kalbin işlevidir. (Leaman, 2012:46) Böylece İslam estetik düşüncesi, ontolojik bir temelde yüzünü, maddenin gelip geçiciliğinden görünüşün ötesine çevirir.

Mimetik kurama karşı gelişen İslam estetiğinde sanatçıdan beklenen şey yoktan var etmesi ya da varlığa getirmesi değil, yaratıcı olmasıdır. Özgürlük ve yaratıcı eylem fikri, İslam estetiğinde önemli bir tartışma konusunu oluşturur. İslam estetiği bu noktada yaratıcılık temelli estetik eylemleri destekler. Bu eylemler kuşkusuz temelde Mimesis'e dayanır. Benzetmenin ne olduğunu düşünelim mi? Üç türlü sedir olmadı mı şimdi? Biri asıl sedir ki onu yalnız Tanr yaratabilir diyebiliriz. (Platon, 2005:597a-d) Kuşkusuz İslam estetiğinde sanatçının "yoktan var etme" eylemi içinde olduğu düşüncesi yadsınır; fakat estetik alanı bu tartışmaya bu kadar yüzeysel yaklaşmaz. Eğer hiçbir yaratıcı eylemde bulunulmayacaksa bu durum Budizm'deki gibi eylemsizlik durumunun getireceği pasif bir nihilizmdir. Bu yüzden İslam estetiği yüzünü nihilizmden yana değil, ontolojik temelde realizme çevirir. Çünkü böylece yaşama dönük yaratıcı eylemlerin de önü açılacaktır. Platon Her şeye bağlı üç sanat vardır: Kullanma sanatı (zanaat), yapma sanatı (poesis) benzetme sanatı (mimesis) demekteydi. (Platon, 2005:601d) Bu noktada İslam sanat ve estetiğinin yaşama dönük zanaat evresinde ortaya çıkan Mimesis işlevseldir ve şu zanaatleri içerir: çömlekçilik, dokuma, süsleme sanatları; yapma sanatı poesis: mimari, köprü, yol, saray, han, bahçeler; benzetme "mimesis" sanatları ise: ebru, hat, minayatür, edebiyat, şiir ve müzikte kullanilır.

İslam estetiğinde temsil ve görsel sanatlar üzerinde var olan yasaklamanın olumsuz etkilerine pek çok yerde vurgu yapılır, fakat bu yasaklamanın diyalektik olarak olumlu bazı getirileri ve sanatçıdan beklentileri de vardır. İslam sanatında "temsil yasăg başlıklarda olumlu gelişmeler olacağı düşünülmüştür.

1. Temsil yasağı yaratıcı zihni yaratıcılık açısından daha çok zorlar. Böylece basit bir nesne taklidi değil, akıl ve duyumları zorlayarak en üst estetik kategoride eser yaratıcıllğını destekleyecek bir adıma vesile olur.

\footnotetext{
${ }^{4}$ E. Said'in kültür emperyalizmi üzerine yapmış olduğu analiz ve ayrıntılı tartışma için bakınız, E. Said, Kültür ve Emperyalizm, İmparatorluk, Coğrafya ve Kültür, s. 33-46 \& Anlatı ve Toplumsal Alan, s. 101 \& Direniş ve Muhalefet, s. 249-305 \& Ortodoksluğa ve Otoriteye Meydan Okumak s.379- 405
} 
2. Zahiri olana değil, Batıni olana yüzümüzü dönmemiz gerekir, çünkü yaratıcılık açısından insan zihninin duyusal bağl1lığı ancak böylece geri plana atılır. Nesnelerin görsel taklidi üzerine yoğunlaşmak, var olanların gerçek özünü ve mahiyetini; varlı̆̆ın, görünmeyen yüzünü kavramamızı güçleştirir. Somuttan soyuta, sanıdan hakikate geçiş ancak bu yolla mümkün olur.

3. Hz. Muhammed ikon kültüründe sanat eseri üretme şekline kesinlikle karşı çıkmıştır. Kendisiyle ilgili ileride oluşabilecek ikonlaşma gelişiminin önüne geçmeyi istediği için böyle bir sınırlandırma ihtiyacı hissetmişti. "Mekke'nin fethiyle birlikte Kabe'deki bütün putlar yıkıld. İsa ve Meryem'le ilgili olanlar hariç 360 put imha edildi." (Artz, 1980:134) Hz. Muhammed, Kabe'yi putlardan temizledikten sonra İsa ve Meryem'le ilgili olanlar hariç çoğunun yok edilmesini emretmiş ve o günden itibaren İslam sanatında insan suretinde resim ve heykeller yapılması yasaklanmıştır. Hz. Muhammed'in bu eylemi yaparken temel gerekçesi, kendisinden önceki dinlerin ve peygamberlerin düştüğü ikonlaşma ve kült bir nesne olma durumuna düşme korkusuydu. ${ }^{5}$

İslam estetiğinin genel çerçevesi içinde düşündüğümüzde somut olanın değil soyut; açık olanın değil "örtük” olanın, yaratıcı aklın düşünsel gücünü arttıracağı için yüceltildiğini görürüz. "Mecaz, hakikatin köprüsüdür", deyimi hakikatin örtük bir şekilde aktarılmasını hedefleyen bir düşüncenin cisimleşmiş halidir. Bununla ilişkili olarak İslam estetiğinin tikel uygulamalarında genel olarak yüceyi ve mutlağı arayış (Bahnassi, 2008:631) kendisini çok net bir şekilde gösterir. $\mathrm{Bu}$ yüce ve mutlak olan görünen şeylerin ötesinde zaman ve mekan ötesi bir kavramsal idealizm ile ancak anlaşılabilir. Platoncu idealizme yüzünü dönen İslam sanatı, daha başlangıçta maddeyi yadsır. Filozof, güzel şeyleri asla güzelin kendisiymiş gibi ele almaz. (Platon, 2005:476c) Güzellik sevgisi, özellikle tasavvufta önemli bir yer işgal eder ve nesneye şekil veren düşüncenin sonsuzluğunda, gelip geçici olanın ardındaki zaman ve mekan ötesi olana yüzünü dönerek düşünsel bir kavrayış ve estetizasyona dönüşür. Benim sorum, güzelin ne olduğuna, onun kavramına, bütün tek tek güzel şeylerin güzelliklerini, ona katılmakla aldıkları şeye yönelir. (Platon, 2000:23) Ontolojisi temelinde gelişen İslam estetiğinde güzel olan ancak Allah'ın kendisidir. Bunun dışındaki tikel canlılar ve ölümlüler ancak ondan pay aldıkları için güzeldirler. Bu da gelip geçici bir görünümdür çünkü er ya da geç tikel-sonluların kendilerinde pay aldıkları "güzel ideası" onları terk eder ve tekrar özüne "Allah"a geri döner. İslam dini, özde güzelden pay alan her şeyi, güzelin kaynağı olan Allah'tan geldiği için en üst kategoride değerlendirmiştir. İ̀lam estetiğinde duyusal güzelden mutlak güzele olan sistematik ayrım kategorik olarak korunmuştur. Fakat duyusal güzelin bir evresi olan "eros" yani, cinsel içerikle, dünyevi aşkla temellenip ilahi olana doğru evrimleşen aşk teorisinde, erosun ilk duyusal evresi, estetiğin itici bir gücü olarak kullanılmamıştır. Bu cesur atılım kendisini ancak "sufi" gelenekte gösterir. Güzel bedenler, güzel bir nesneden değil, güzel ideasından pay aldıkları için güzeldirler. Düşüncenin, nesnelleşmiş hali, onda, maddesel ve sonlu olarak açığa çıkar. Bu nesnelleşme hali Eros'un, dünyevi aşk evresinden, mutlak olana evrildiği, dünyasal olandan uzaklaşıp mutlak olana yöneldiği estetizasyonlarda görülür. Bu noktada İslam estetiği kendisini, dünyevi ve tekil canlıların sonlu güzellik deneyim ve tecrübesini değil, mutlak olanda kendisini yok etmeye hazır, Allah aşkında nesnelleştirmektedir. ${ }^{6}$

Platon sanat kuramı yazarın yaşlılık döneminde özellikle Timaios evresinde geometrik formları yüceltmeye ve matematiksel düzlemde form bulan, estetik üretimi daha ön plana çıkartmaktayd1. ${ }^{7}$ Bunlar (yani bu düzeyler ve çemberler) başka nesnelerde olduğu gibi, bir başka şeye göre güzel olmayı, daima ve daima vardırlar; kendi başlarına güzeldirler ve bunlar özleri

\footnotetext{
5 Alamı Hamdouni Muhammed (2015) The Origins of Visual Culture in the Islamic World, Aesthetics Art, and Architecture in Early Islam, An Aesthetic Revolution: From Trance to Meaning-a Matamorphosis of Islamic Aesthetics, Ayrıntılı tartışma için bakınız, s.19-39

${ }^{6}$ Yeni Platoncuların her şeyin kendinden türediği "Bir" fiiil'i bir varlık olmasa da tektanrıcılık ve tevhid konularında İslamla hem fikirdir. Ayrınıtılı tartışma için bakınız, Leaman: 2012:41

$7 \mathrm{Bu}$ yönüyle Platon, Whitehead'ın değimiyle: modern bilim ve sanata daha yakın tespit ve değerlendirmelerde bulunmuştur. Whitehead: 1975, Science and Modern World, s.40
} 
gereği güzeldirler ve belirli, kendilerine özgü bir haz duygusuna götürürler. (Platon, 1998:51) İslam sanatı bu geometrik formların kullanılması noktasında Platon'u aynen takip eder. İslam sanatı kahir ekseriyetle saf geometrik biçimle temel canlı şekillerini temel alan biçim olarak adlandirllan şey arasinda dengedir. (Leaman, 2012:30)

$\mathrm{Bu}$ noktada İslam sanatının geometrikleşmesinin üç temel nedeni vardır. Birincisi; Platon'dan gelen Timaiosçu etki ve bunun formsal yetkinlik düşüncesi, İkincisi; İslam ontolojisi açısından insan ve canlı nesnelerin taklidinin kesin bir şekilde yasak olmasının yarattığı boşluğun doldurulmasıyla ilgili arayış. Üçüncü olarak: temsil yasağının sanatçının imgesel yaratıcılığını daha da geliştireceği düşüncesiyle yapılan estetik amaçlı düzenleyici müdahale.

\section{Aristoteles- Her Tuğla Olduğunda Ne Olmak İster?}

İslam kültürü daha başlangıçta kendisini akılsal bir temele yerleştirmek ister. Kur'an-1 Kerim'de müminlerden öncelikle "düşünmeleri, evreni-varlı̆gı ve kendilerini bilip tanımaları istenir. Estetik amaçla yapılan yaşama dönük sanatsal yaratıcılık temelli eylemler, dünyayı daha güzel kılma amacıyla yapıldığı için temelde desteklenirler. Aristoteles'e göre insanın üç temel özelliği vardır: Bilmek, yapmak ve yaratmak (Episteme, praxis ve poesis) (Aristoteles, 1996, VI1025B) Burada dikkat çeken fiil, "yaratmak" eyleminin imkan ve sınırları ile ilgilidir. Burada Aristoteles'in sorguladığ 1 şey "yoktan var etmek" değil, poetik anlamda "yaratıcıllğın doğasını ve sınırlarını" sorgulamaktır. Fakat bu kavram, İslam estetiğinin orta döneminde, ideolojik gerekçelerle farklı bir düzleme çekildiği için Aristoteles'in düşündüğünün çok uzağında değerlendirilmiş, poetik meydana getirme, yoktan var etmek olarak anlaşılarak, estetik alanında önemli bir çekinceye neden olmuştur.

Aristoteles'e göre poetik yaratma, yoktan var etmek değil, verili bir malzemenin, kendi iç yasalarıyla yeniden biçimlendirilerek akılsal bir soyutlama ile nesnede, tinsellik kazandırılarak oluşturulmuş yapay bir yaratıdır. Sanat, insan zihninden çıktığı için entelektüel bir değer taşır. Sanat eseri olandan varlığını alan, (madde-form) insan tini ile düşünülmüss, elleriyle yapılmış, doğada var olmayan, yeni bir üretimdir. İnsanın doğaya sanat aracilığıyla eklediği şeyler, İnsan düşüncesi ve eliyle doğaya yeni bir katkıdır. Bu noktada Aristoteles'e göre insan düşüncesinin teleolojik işlevi poetik yaratma evrimi sayesinde bugünkü halini alır. "İnsan neden ev yapar?" sorusuyla, "insanın neden elleri var?" sorusu ontolojik olarak birbiriyle ilişkilidir. Çünkü Aristoteles'e göre sanat, gerçek akıl tarafindan yönlendirilen bir tür üretme yetisidir. (Aristoteles, 1998:1094a) Bu üretmeninin temel amac1, verilenden hareketle insanlığa faydalı olacak yeni ürünler ortaya koymak, çalışmak ve yaratıcı olmaktır.

İslam estetiği sanatsal yaratmaya kesin bir sınır koymadığ gibi aksine, sürekli bunu geliştirmek ve teşvik etmek istemiştir. Bu noktada aslında Müslüman sanatçının yaptığı şey Aristoteles'in vurguladığı düşüncenin benzeridir. Müslüman sanatçının amacı da yaratmak değil, yaratıcı olmaktır. (Bahnassi, 2008: 636) Bu düşünce, tam da Aristoteles'in vurguladığ1 "akll tarafindan belirlenen amaçların gerçekleşmesini, varlı̆̆a gelmesini să̆layan bir yapma-yaratma yetisidir" (Aristoteles, Metafizik: 1996:IX-1046a5-1046b28) ve ayn1 zamanda estetik üretime geçişin de en güzel örneğidir. Bu noktada İslam estetiği sınırları içinde aslında poetika'ya bakış Aristoteles'in değerlendirmelerinin çok da uzağında değildir. Çünkü bu kültür için de poetika en genel anlamıyla, yaşama sanatı ve bilime karşıt olarak yararlı ve güzel sanatlart içerir. (Ross, 2002:319) Aristotelesçi bu bilime karşı yararlı ve güzel sanatların olgunlaştırıcı etkisine yapılan vurgu, İslam estetiğinde olumlu bir etki yaratmıştır. Bilim ve felsefenin kavramsal metodolojisine karşı, sanatsal üretim alanının hem etik-pedagojik hem de estetik (duyusal) ve entellektüel yönü böylece daha ön plana çıkmaktadır.

İslam sanatında "tiyatro-trajedi" gibi "insanı eylem içinde" gösteren bir sanat formu da gelişmemiştir. Sanatsal temelde, insan eylemlerinin evrenselleştirilmiş taklidi yoktur. Çünkü "insan ve insan temelli taklit" ve Aristotelesçi tragedyanın en önemli işlevi olan "ahlaksal içerikli ve 
tanrısallı̆̆ı seyri" eylemlerinin taklidi ya da temsili durumu daha baştan engellenmiştir. "Eylem içinde insan" taklidi noktasında karşımıza tragedya ve dans sanatları çıkar. Birincisinde katharsis işlevi, estetik tecrübe olanağını, tragedyadan politik alana doğru değişim geçirir ve yaşamsal eylem ve trajik olanın seyri noktasında önemli bir dönüşüm geçirir. İkincisinde ise, din ritüeline özellikle Sufiliğin "sema" ayinlerinde dinsel seramoniye taşınır. ${ }^{8}$ Sufizmin sema ayinlerindeki ses ve ritmik beden hareketleri, eylem içinde insan taklidini değil, evren-gerçeklik ve varoluşun temsilini içermektedir.

Aristoteles'se göre sanat eseri insan eliyle doğada var olan eksikliğin giderilmesine katkıda bulunur. Hatırlayacak olursak Aristoteles'e göre bütün insanlar doğal olarak bilmek ister ve bundan haz da alırlar. İşte sanat yoluyla meydana gelen bütün bu bilme temelli etkinliklerde böylesi bir epistemik ve estetik bir haz ortaya çıkmaktadır. Bu düşünce İslam düşüncesinde dünyayı güzel kılma amacıyla yapılan pek çok çalışmanın itici gücü de olmuştur. Bu müdahaleler aslında basit düzenlemelerden ibarettir, yapısal ve büyük dönüştürücü eylemleri içermezler. Çünkü İslam düşüncesine göre kainatta insan eliyle tamamlanacak her hangi bir "eksiklik" yoktur. Allah, bu kainatı en mükemmel şekilde yaratmıştır. İslam düşüncesinde yetkinlik açısından bu dünya, Leibniz'in de düşündüğü gibi “olanakllların en mükemmelidir.” Herhangi bir eksikliğin bu kainatta var olduğunu ileri sürmek Allah'ın varlığını reddetmek ya da yetkinliğini sorgulamak demektir. Bu düşüncenin etkisiyle İslam düşüncesinde evren rasyonalizasyonuna bakış, çok farklı bir zeminde gerçekleşmektedir. Aristoteles açısından düşünecek olursak örneğin bir evi ele alalım, bu evin var olmasının temel nedeni, evin oluş sürecini de belirler. Bu aktif bir süreçtir. Aristoteles'e göre: Bir evin yapımı için bir fiil bir ev gerekmez. (Aristoteles, 1996:Z1032b1:61) Doğal ve kendiliğinden meydana gelmelerde insanın yaratıcı etkinliği yoktur fakat insani yaratılar söz konusu olunca, insan düşüncesi teleolojik olarak ilerler. Aristoteles'in ünlü sözü "her tuğla olduğunda başka bir şey olmak ister" cümlesi "madde ve form" kuramı ve teleolojik ilerlemenin bir sonucu olarak karşımıza çıkar. İslam estetiği, bu kültürel olarak ilerleyen teleolojik dönüşümü doğru anlamıştır. Hıristiyanlık, Yahudiliğin bir benzeri olmaktan, onun kültürel olarak yeni bir yorumu olmay1 aşamamış, kendisini (Yeni Lahit), oluşum sürecinde tamamladığında başka bir şeye (yerini aldığı şeye) dönüşmüştür. Hıristiyanlık, karşıtını düşünse de Yahudileşmek (eski Lahit) ya da onun gibi mitik-kültürel bir senteze dönüşmek zorunda kalmıştır. İslam kültürü için de en büyük sorun böylesi bir dönüşümün gerçekleşme ihtimalinin korkusudur. İslam, kendi oluşumunu tamamladığında yeni bir Hırıstiyan kültürü olmayı istemez. Bu yüzden Aristoteles'in "her tuğla olduğunda başka bir şey olmak ister" yargısının Hristiyanlığın devamı olan bir İslamiyet noktasında değil, fakat ona antitez olmayı isteyen bir İslam kültüründe açık bir şekilde görürüz.

\section{İslam Sanatında Temsil-Kendindelik ve Optik Perspektif}

Mevlana'nın Mesnevi'de geçen bir hikayesi vardır. Çinliler ile Yunanlılar arasında bir resim yarışması düzenlenir. Çinliler yüzlerce renkle bir resim yaparlar Yunanlılar ise sadece yapılan resmi daha büyük ve parlak gösterecek bir ayna yaparlar. Böylece yarışmayı Yunanlılar kazanır. Bu öyküde verilen mesaj Platon'un Devlet'te verdiği örneğin bir benzeridir ve mimesisin duyusal ve rasyonel sınırlarını açık bir şekilde gözler önüne serer. "İstersen bir ayna al eline, dört bir yana tut. Bir anda yaptın gitti güneşi, yıldızları, dünyayl, kendini, evin bütün eşyasını, bitkilileri, bütün canlı varlıkları." (Platon, 2005:X:596e) İslam estetiği, daha başlangıçta ontolojik bu tartışmanın içinde Platon düşüncelerinden yana tavır almıştır. Çünkü sonlu ve değişim içindeki nesnelerin taklidini yapmanın yaratıcılık açısından bir önemi yoktur. Daha önce de belirtildiği gibi

\footnotetext{
${ }^{8}$ Schimmel Annemarie, (1982) Tasavvufun Boyutları, ayrıntılı tartışma için bakınız.
} 
temsil yasağı, sanatçıyı, zihinsel olarak daha çok zorlamak amacıyla oluşturulmuştur. Ayrıca, nesnelerin görsel taklidi üzerine yoğunlaşmak, var olanların gerçek özünü ve mahiyetini, varlığın görünmeyen yüzünü kavramamızı da güçleştirir.

İslam estetiği, ontolojik ve epistemolojik gerekçelerle sıradan taklide yasak koymaktadır. Mimetik bu yasaklamanın olumsuz bir etkisi perspektif geleneğinin gelişmemesinde kendisini göstermiştir. Tasvir ve taklitle ilişkili olduğu ve yaratıcıllı̆g engelleyeceği endişesiyle İslam'da perspektif geleneği gelişmemiştir. (Bahnassi, 2008:639) Fakat optik geleneğin oluşmaması sanatsal ve görsel bir ifade aracı olarak görsel sanatlarda hiçbir ilerleme gösterilmediği anlamına gelmez. İslam düşüncesinde optik perspektif, “merkezi bir sanatçı” kavrayışına, merkezi bir "domine eden öznenin bakışına" aittir ve bu özne oluşumuna İslam estetik düşüncesi daha başlangıçta epistemeontolojik gerekçelerle karşı çıkar. Sanatsal ifade edişin evrensel ve tek bir ilerleme yönü olduğu ve bunun da ancak batı sanatında kendisini gösterdiğine dair var olan Avrupa merkezcil bakışın getirdiği tek yanlı ve eksik bir evrenselleştirme idealine karşı geliştirilen en radikal, en iddialı karşı tez İslam estetik düşüncesinden kaynağını alır. Evrensel ölçekte bakacak olursak estetik tarihinde, batı estetik ilkelerinin dışında gelişen pek çok optik perspektif geleneğin bulunduğunu görürüz. Örneğin; Çin sanatında perspektif, okuyucuyu ve izleyici resmin ortasına yerleştirir: Bakış açısı özneye göredir, böylece uzaktaki nesneler ön plandakilerden daha büyük görünürler. Hint sanatında perspektif, okuyucunun arkasından alınmıştır. Ama manevi perspektif tamamen farkl bir prensibe dayanır. (Bahnassi, 2008:63) İslam sanatında ise temel sorun, anlatının ve temsilin varlığıyla ilişkilidir. Çünkü: Bu düzeyde Islam medeniyetinin sanatı da anlatının olmadiğl, ikonsuz bir sanattır. (Leaman, 2012:39) Aslında İslam estetiğinde perspektife karş1 olmanın temel nedeni sanatçının yaratıcılık eyleminde belirlenimleri yıkmak ve sınırları "duyusal ve rasyonel" olarak genişletmek amacıyla yapılmıştır. Bu yüzden İslam estetiğinde temel doktrin, sanatçıyı bilinenin aksine, sanatsal yaratıdan uzaklaştırmak amacıyla değil daha soyut ve formel yaratıcılığa zorlamak amacıyla yapılmıştır. Bu amaçla İslam geleneğinde "Ressamın nesnesine bakışı, belirli bir açıyla sınırlandırılmaz, evreni, bir bütün olarak algılamak ister. (Bahnasi, 2008:640) Bu bütüncül bakış aslında Allah'ın varlığının kavranması çabasında var olan Yeni Platoncu BİR kavramıyla koşut düşünülmektedir.

İslami perspektifte slcak ve soğuk, nemli ile kuru arasindaki dört katmanl eksen etrafinda dönüp duran temel bir simetri mevcuttur. (Leaman, 2012:31) İslam estetiğinde simetrinin olmadığını, hiçbir suretle resim yapılmadığını, düşünmek büyük bir yanılgıdır. Belirli bir kısıtlamanın olduğu muhakkaktır, ancak insanın çizme, imgesel düşüncesini, estetize etmediğini düşünmek, Heidegger'in deyişiyle düşüncenin kendisini yadsımasıdır. İslam estetiğinde resim yasağının temel gerekçesi estetik değil aslında ideolojiktir. Sanat ontolojisi açısından ya da estetik bir kriterden ötürü değil, fakat temelde Hırıstiyan ve Romalıların yapmış olduğu gibi "ikon-put" ya da Hırıstiyan ikonlaştırıcı kültlerine benzeme korkusu, İslam kültürünü zorunlu olarak suret yasağına itmiştir. Çünkü her iki kültürel yapıda karşımıza "nesnelleşmiş bir tanrı-baba" modeli çıkmaktadır.9 "Tanrının sanat yoluyla cisimleştirilmesi", Yunanlılar gibi "insani bir surete" sokulup yeryüzüne indirilmesi çabasına karşı bir hamle olan bu suret yasağının daha sonra niteliği ve sınırları genişletilmiş, basit bir şekilde resim yasağı algısına dönüşmüş, ne yazık ki bu alandaki yaratıcılığın da olumsuz bir şekilde önüne geçerek, İslam sanatçılarında derinlik algısının gelişmesini olumsuz yönde etkilemiştir.

İslam kültüründe resim sanatının yasak olduğu kanısına karşı temelde soruyu şöyle sormamız gerekir. Heykel ve Resim gibi iki ve üç boyutlu sanatlarda kaç türlü perspektif kullanmıştır ve bunun ontolojik temellendirmesi nasıl yapılmıştır? Batı heykel ve resim geleneğinde iki türlü perspektif ortaya çıkmıştır. Bunun ilkini Heidegger ve Nietzsche'nin

\footnotetext{
${ }^{9}$ Hıristiyan sanatını tarihsel süreç içinde diyalektik bir zamansallık içinde değerlendiren Hegel, Hıristiyan sanatındaki bu Baba-Tanrı modelinin gelişiminin estetik ve ontolojik analizini yapar, ayrıntılı tartışma için bakınız, G. W. Hegel, Estetik, Cilt 1., İdealin Belirlenimliliği, s.173, Bir Tanrılar Topluluğu Olarak İlahi Olan, s. 174
} 
(Nietzcshe, 1995:23) yüceltmiş oldukları Yunanlılar oluşturmuştur. Bu optikte merkez, "bakan ve bakılanın" konumlanması insanüstü bir ilahi güç temelinde oluşmuştur. İnsan, burada kendisine bakılan-izlenen, yani varlık tarafindan seyredilendir, pasiftir. Fakat bu perspektifi bulanlar da doğrudan Yunanlılar değildir. Çin, Hint, Mısır sanatında bu optik perspektifin nüvelerini görürüz. Tanrısallığın seyri noktasında "özne" olamamış tikel sonlular, bakılan-seyredilen bir modeldir ancak. Sanat yapıtında, yani "sanat eserinde yansıyan "insan bedeni" (özellikle Yunan heykeliHegelci açıdan düşünecek olursak en mükemmel örneği) sadece bakılan, seyredilen bir evrenselin, tikelleşmiş halini temsil eder. Bu dönemde "bakan ya da bakılan", "özne ya da varlık" estetik algının merkezinde değildir. İslam estetiğinin temel bakışı bu perspektife biraz yakın olsa da tam olarak böylesi bir "tanrısallık-insan-varlık" üçgenine indirgenmezler. Aslında zaten İslam düşüncesi bu temelde bir estetizasyona da karşıdır. "Tanrının görünür kılınması" çabası ve "tanrıinsan; sonlu-sonsuz" mücadelesini anlatan bu felsefi-mitik ve mimetik temelli "temsile" başlangıçtan beri mesafeli yaklaşılmıştır. Bu yüzden İslam estetik eserlerinin tikel karakterini değerlendirirken bu düşünceden hareketle yargılama yapmamız daha doğru olur. İşte bu yüzden İslam geleneğinde, batı tarzında "resim" yoktur, fakat "minyatür, hat, ebru", gibi görsel ve iki boyutlu form estetiğini kullanan tikel sanatlar renk ve geometrik form düzleminde bulunmaktadır. İslam sanatı bunu aşmak için konuya odaklanan minyatür sanatını geliştirmiştir. İslam minyatür ya da basit resim denemelerinde ışık yoktur. Perspektif yok denecek kadar az neredeyse yoktur. Özne konumlanması da yoktur. (Leaman, 2012:53 Ayrıca İslam estetiğinde, sanatçının "özne" olmak gibi bir çaba ve düşüncesi de yoktur. Böylece merkezi özne ya da yasa koyucu olan sanatçının perspektifsel bakışı oluşmaz ve tek boyutlu bir estetik algının içine alımlayıcılar zorunlu olarak sokulmazlar.

Batı sanatında diğer önemli optik perspektif değişimi Rönesansta ortaya çıkar. Rönesans, bilindiği gibi hemen ardından "hümanizm" akımını getirecektir. Bu dönem aynı zamanda feodalitenin çözülmesine bağl gelişen burjuvanın, kapitalizmin ve Aristokrasinin kendisini sanatta algılama biçiminin en güzel örneği olan, görsel sanatlarda perspektif algısına bağlı olarak ortaya çıan "temsil" sorununda ve kapitalist, özne-nesne ilişkisinde de gösterir. Temsil, aynı zamanda kapitalist düşüncenin en tipik özelliği olarak da karşımıza çıkar. Şeylerin varlığı ve dönüşümünü sağlayan temel ilke bu dönemde temelde değişir. Rönesans'ta var olan perspektif geleneğinin değişmesinin kaynağı batı kültüründeki düşünsel-sosyal ve ekonomik değişimlere paralel değişen sosyo-sınıfsal farklılık ve aristokrasinin kendisini algılama ve temsili düşüncesiyle belirlenmiştir. Batı estetik tarihinde öznenin bir sanat yaratıcısı olduğu iddiasına karşı sav ancak 20.yy. başlarında yapısalcılığın, post yapısalcılığın ve postmodernizmin eleştirileriyle gündeme gelmiştir.

Perspektifi belirleyen bir diğer önemli faktör de sınıflı toplumsal yapıdır. Ruhban sinıfi olmayan Müslümanlarda kültürün kimliğini koruyabilmesi ancak ahlak ve metafizik yardimıyla olmuştur. (Grabar, 2018:214) İslam kültürü, toplumsal yapılanmasında sınıfsal bir bölünme barındırmadığ için ${ }^{10}$ "kutsal, ruhban sınıfi, aristokrasi, kral ve burjuvazinin" temsili sorunu ortaya çıkmamış ve bu tür sosyo-ideolojik gerekçeleri, sanat eserlerinde ve mekan bölünmelerinde "temsil, gösterge ya da metaforlarla" göstermek için bir neden kalmamış ve İslam sanatında böylesi bir tecrübenin olanağı daha başlangıçta yok edilmiştir.

\section{Uzamsal Mekan'dan Kutsal Mekana}

İslam mimarisi denildiğinde akla, Suriye-Mısır, İspanya, Kuzey Afrika'yı içine alacak şekilde mağribi, İran, Osmanlı ve Hint (Settar, 1955:4) gelir. İslamiyet'in doğduğu yıllarda Arap yarımadasında mimari bir yapı bulunmamaktaydı. (Settar, 1955:4) Müslüman kültürün mimari sanatıyla karşılaşması hazreti Ömer zamanında gerçekleşir. O zamana kadar mimariye doğrudan ihtiyaç hissedilmemiştir çünkü ilk dönem Müslümanlar Camilerde değil, yeryüzünün her yerinde

${ }^{10}$ Görsel sanatlar her zaman belli bir koruyucu kabuk içinde olagelmişlerdir; başlangıçta bu kabuk gizemli ya da kutsal bir şeydi. Sonra sanatın sarıldığı kabuk toplumsal bir şey oldu. Yönetici sınıfların ekinine girdi. Bu arada bu sınıfın yaşadığı saray ve evlerin içinde insanlardan ayrıldı. J. Berger: Görme Biçimleri, s.32 
namaz kılabilmekteydi. Gök kubbenin altında bütün Müslümanların kutsal mekanıdır. Buna, İslam açısından yerin temellük edişi de diyebiliriz. Mikro ve makro evren, ahengini ve metaforunu İslam mimarlık geleneği özellikle camilerin tasarım ilkelerinde aynen kullanmışlardır. "Mimarlar, caminin minyatür bir evren timsali olduğunu anlayarak tepesinde göğ̈ temsil eden bir dam, sembolik bir giriş ve bu küçük ölçekli dünyayı Mekke'deki Kabe'ye bağlayan bir koridor olarak mihrap ve göklere doğru yükselen sivri minarelerle bir ibadethane yaptılar. ${ }^{11}$

Batı mekan sanatlarında boşluk, formalist estetik açısından strüktürün bir parçası olarak görülürken İslam mekan sanatlarında "boşluk" öncelikle ontolojik ve daha sonra epistemolojik gerekçelerle yadsınan bir estetik kategori olarak görülür. Boşluk korkusu (Horror Vacui) İslam düşüncesinde çeşitli nedenlere dayanmaktaydı. R. Ettinghusen'e göre, İslam estetiğinde boşluk kavramına tepki verilmesinin temel üç nedeni vardı. (Leaman, 2012:133) düşüncesi.

1. Büyük İslam şehirlerinin aşırı kalabalık olması ve bunun sanata da yansıması gerektiği

2. Çölün boşluğu ve bu boşluk duygusunun yarattığı rahatsızlık.

3. Araplara özgü mübalağa eğilimi, estetik tasarımlarda tıka basa dolu tasarımlarda kendisini gösterir. (Leaman, 2012:67-69)

\section{Ayrıca biz şu maddeleri ekliyoruz:}

4. İslam ontolojisinde var olan kainatın Allah'ın varlığı ile dolu olması düşüncesine karşıt olacağı için "boşluk" kavramına karşı mesafeli yaklaşılır.

5. Aristotelesçi bir ontoloji ile "doğa, boşluk kabul etmez" düşüncesi estetik alanında da kendisine yer bulur ve dolu bir evren düşüncesine paralel, boşluğu yadsıyan, doluluk kavramını estetik bir ilke olarak yücelten bir eser yaratma düşüncesi gelişir.

6. İslam, estetik alanında sembolik bir dil geliştirmemiştir. Bu yüzden boşluk-doluluk kontrastı temsil ya da sembolizm, mekan sanatları içine girememiştir.

İslam kültüründe sosyal olarak yapılan ibadet sayısı oldukça azdır. Cuma namazı ile bayram namazı ve Hac dışında birlikte yapılan bir ibadet yoktur. Aslında İslam kültüründe camiler öncelikle, sosyalleşme-kültür ve eğitim amacıyla yapılan yerleridir, çünkü: cami, kültür yayan bir merkezdir. (Bahanasi, 2008:648) Kollektif olarak inananların sürekli bir araya gelme imkanı kısıtlıdır. Fakat ilk dönemlerde camilerin önemli bir sosyalleşme mekanı olması düşüncesi vardır. Hz. Muhammed aslında camilerin bir kültür, sosyalleşme ve yaşayan mekanlar olmasını istemiştir. (Settar, 1955:3) Bu etkiyi daha sonraki camilerin genelinde görürüz. Camilere, genelde büyük olanlara kütüphane, mektep, fakülte, (medrese) öğrenciler ve gezginler için bir imaret, muhtaçlar için aşhane, hamam, yıkanma odaları, bazen de önemli kişilerin mezarları eklenmiştir. İlk dönemde camiler aşırılık düşüncesinden, gösteriş ve süslemeden uzaktır. Mimari yapıda dış cepheyi önceleyen Batılı tavrın aksine, geleneksel İslami mimaride kaygı mekanın içinde yaratılacak histe yoğunlaşır. Bunun sonucu ise mekandaki yapıdan ziyade bizatihi mekanın kendisiyle ilgilenen iç mimaridir. (Leaman, 2012:181) Anlaşıldığı gibi İslam mekan sanatlarında özellikle kaşımıza ilk çıkan yapı camilerdir, daha sonra saraylar, kervansaraylar, hanlar, medreseler, köprüler gelmektedir. İslam mimarlık geleneğinde hem üslup hem de dönem olarak klasikleşmiş bir dönemin olmadığını görürüz. Bu mimari gelenek yokluğunu tümüyle İslam'a özgü bir saray tipi olmadı̆̆ı gibi İslami bir kent formunun gelişmemesinde de görürüz. (Grabar, 2018:214)

Camilerin yapılma sürecinde kıble yönü ve İslami ay takviminin evrensel ölçekte hazırlanması amacıyla astronomi biliminde önemli gelişmeler olmuştur. (Artz, 2012:127)

\footnotetext{
${ }^{11}$ A. Bahanasi, Sanat ve Estetik Yaratıcılı, (Derleme) İslam Kültürü, Böylece dinsel estetizasyon sürecinin mekan sanatlarında dönüşümü de başlamıştır. s.650
} 
Kuşkusuz camilerin yapılması sürecinde İslam bilginleri pek çok disiplinden yararlanmışlardır. Coğrafya, astronomi, geometri, fizik ve matematik bunların başında gelir. İslam tasarımcıları, cami ve mimarlık konusunda çeşitli semboller ve temsiller içeren bir mekansal bölünmeyi çok tercih etmemişlerdir. İslam kültürü kendisini oluştururken mitlerden özellikle uzak durmuştur. (Grobe, 1983:23) Hiristiyan-Grek ve Roma'daki gibi mitsel bir kültürel sentez yapma fikri İslam kültüründe pek hoş karşılanmamıştır. (Grobe, 1987) ${ }^{12}$ Güneşin bir tanrısallık temsili olarak kabul edilmesi, buna bağlı gelişen takvim yapma şekli ve bu işlemde referans alınan temel öğe yönünden de Batı ile İslam arasında yapısal bir farklılık oluşmaktadır. İslam estetiğinde ışık nesnelerin özü olarak kabul edilir. (Bahnassi, 2008:642) Bu anlamda mimarlıkta da 1şı önemli bir estetik unsurdur fakat İslam sanatı, batı estetizasyonundan farklı olarak "1şığı" tanrısallaştırmaz.

\section{Şiir- Müzik Karşıtlığı ya da Koşutluğu}

Erken dönem İslam estetiği üzerine düşündügümüzde "mimarlık ve müzik" sanatlarının diğer sanat türlerine göre daha büyük bir ilerleme kat ettiğini görürüz. İslam estetik düşüncesinde ve algısında müzik, hiçbir zaman salt müzik olarak ele alınmaz. Kutsal kitap Kur'an'1 Kerim esasında şiirsel bir kitaptır ve onun okunuşu "şiirsel-müzikal" bir estetik duyarlılık gerektirir ve bu noktada İslam daha başlangıçta şiirsel ve müzikal bir temelde kendisini estetik olarak duygusallaştırır.

Kurân-1 Kerim "Oku” emriyle başlar. Okumak, sese dayanan ve sesle ilgili işitsel bir kültürün gelişmesinin temeli olmuştur. Bu noktada "ses" batı düşüncesinde var olan elementer yapıda "1şığın" karşıtı olarak düşünülmüştür. Bu noktada enstrümental sesten daha çok, insan sesinin metafizik yönüne vurgu yapıldığını görürüz. Bu noktada 'Kur'an'ın anlatım biçiminin şiirsel olduğunu da unutmamamız gerekir. Şiir, aynı zamanda mantıksal-lojik bir açığa çıkma ve anlamanın bir aracıdır aynı zamanda. Çünkü: Meşşai düşünürleri, şiiri, mantığın en zayıf biçimi olarak görürler. (Leaman, 2012:132) anlaşıldığı gibi şiir, kendisinde bir hakikat değeri taşır ve varlığın-hakikatin Heideggerci anlamda bir açığa çıkışının aracı da olur. Bu yüzden İslam estetiğinde hem şiir hem de müzik karşıt sanatlar olarak değil birbirinin içinden doğan sanatlar olarak anlaşı1ır.

İslam kültürü daha başlangıçta "sözel" bir kültür olarak gelişmiştir. Söz, aynı zamanda Yunan felsefesindeki gibi "logos-akıl” kavramını da içermektedir. İslam geleneğinde Kur'an'1 Kerim'in yazımı kadar okunuşu da önemli bir uzmanlık alanı olmuştur. Kutsal kitabı, gelişi güzel değil, "armonik ve müzikal" olarak, insan aklı ve ruhuna hitap edecek bir şekilde özel bir "tını" ile okumak gerekir. Bağlantılı olarak ezanın okunuşu da bu anlamda estetik ve müzikal bir şekilde olmalıdır. Buna bağlı olarak şiirle ilgili "edebiyat ve yazı" sanatları da kendi içinde ilerleme gösterirler. Şiir, bu anlamda edebiyat sanatlarıyla paralel gelişerek estetik bir oluşumun taşıyıcısı olur. $\mathrm{Bu}$ noktada İslam estetiğinde, müzik ve şiir birlikteliği ya da karşıtlığı tartışması, Schopenhauer, Nietzsche, Schelling, Hegel hattta besteci Beethoven ve Wagner'dekine benzer şekilde ama onlardan yüzlerce yıl önce benzer şekilde gündeme gelmiştir. ${ }^{13}$ Müzik ve şiir koşutluğu ya da karşıtllğg önemli bir estetik doktrin değişiminin de başlangıcı olarak kültürü şekillendiren temel bir öğe olmuştur.

İslam estetiğinde müzik özel bir konumdadır. Özellikle Pisagorcu etkiyle "küreler, gezegenler ve matematik ve sayıların" ifade aracı olarak da görülür. İslam estetiğinde "ses"

\footnotetext{
${ }^{12}$ Ayrıntılı tartışma için bakınız: Grobe E., What is Islamic Architecture? Architecture of the Islamic World (1987) \& Grabar, The Iconography of İslamic Architecture, s. 53

${ }^{13} \mathrm{Bu}$ konuda müziğin şïrden üstün olduğu tartışmasının en önemli temsilcisi olan Nietzsche, Schopenhauer gibi müziği üstün bir sanat olarak değerlendirmekte ve ontolojik tartı̧̧mayı bu yöne çekmektedir. Tragedyanın Doğuşu'nda bütün sözel sanatlarının gelişimini müzikal, sanat kökeninden gelecek şekilde değerlendirerek müziğe üstünlük vermektedir. Ayrıntılı tartışma için bakımız, Nietzsche F. W. (1995) The Birth of Tragedy (Transleted by C.P.Fadiman) Dover Publication, New York - London
} 
kavramına özel bir şekilde, kutsal bir element olarak yaklaşılır. Çünkü "ses”, ilahi bir nefesin, yaşamın, kısacası bütün evrensel varoluşun bizatihi kendisini temsil eder. Müzik İslam estetiğinde hiçbir zaman salt bir eğlence aracı olarak görülmemiştir. İslam müzik kuramcıları, müziğin metafizik, felsefi, kuramsal ve matematiksel gelişiminin insanın manevi yönüne etkisi üzerinde değerlendirmelerde bulunmuşlardır. Ayrıca bu etki o kadar kuvvetlidir ki batı kültürünü de etkiler. Müslüman yazın, sanat ve müziği batıyı etkiledi. Müslüman yazından Troubadourlar, Trouvereler ve Minnesinger'lerin yalnızca temalarının bir bölümü değil, ama yaşam ve sevgi üzerine görüşleri de geldi. (Artz, 1980:146) Böylece İslam müzik geleneğinde müzik gelişim seyri hem dini hem dünyevi temalarla ilerlemeye başlar.

İslam müzik geleneği iki farklı kuram temelinde gelişir. Birincisi: İhvanı Safa ile El Kindi'nin düşünceleriyle oluşurken diğeri Farabi ve İbn-i Sina 'nın düşünceleriyle oluşur. El Kindi ve Ihvan'a göre müzik Pisagorcu bir temelde matematiksel ve mistik olarak gelişir. El Kindi'nin müzikle ilgili temel metinlerini şöyle tasnif edebiliriz:

El risale-el Kubra fil-te'lif,

Risale fi tertib al nağm el dalle ala taba'i el-eşhas el aliye ve teşabuh el-te'li,

Risale fi medhal ila sina at'el-musika,

Risale fi-l-ika,

Risele fi medhal ila sina at el-te'lif,

Risale fi sina at el-shir,

Risale fi ahbar ala sina at al -musika,

Kitabu tertib el-nă̆m,

Mutasar el-musika fi te'lif el-nagm el sina at el-ud,

Risale fi ecza haberiyye fi-l musika.

Farabi ve İbn-i Sina ise müziği sadece dinleyicide oluşturduğu estetik haz ile ilişkilendirir ve müzik, daha dünyevi bir temelde kabul edilir. (Leaman, 2012:154) Farabi olarak bilinen, aslen Özbekistan Farab kentinde doğan ama asıl adı: Ebu Nasr B. Tarhan (870-950) olan Farabi, çok iyi bir ud çalgıcısı, besteci, önemli bir müzik kuramcısı ve aynı zamanda önemli bir düşünürdür de. Farabi, müzik alanında şu eserleriyle bilinir:

El-Musika el Kebir,

İhsa el-ìka,

Kitab el-Nakra,

El-Kalem fi el-Musika.

Önemli bir düşünür, müzik kuramcısı ve tıp alanında hem doğuda hem batıda neredeyse sekiz asırlık bir otorite olan İbn-i Sina'nın içerisinde müzik ile ilgili konuların da olduğu ilgili eserleri şunlardır:

Kitab el Şifa: İstanbul'da Süleymaniye kütüphanesinde muhafaza edilmektedir.

Kitab el-Necat,

Danişname,

Risale fi takasim Al-Hikme.

Bu iki farklı müzik kuramı, müzik felsefesinde var olan temel iki kuramsal tartışmanın da temelidir. Bir tarafta matematiksel-soyut ve mistik müzik kuramı; diğer tarafta ise müziğin estetik 
bir amaçla, estetik bir zevk için yapıldığını düşünen seküler müzik kuramı. Bu noktada İslam müzik kuramı temelde bu iki perspektifte gelişmiştir. El kindi ve ihvan için önemli olan müziğin neyi yansittı̆̆ iken Farabi ve İbn-i Sina için ise müziğin bizim için ne yaptı̆̆ıdır. (Leaman, 2012:154) Müzik estetiği açısından çok güncel bir tartışma konusunun nüvelerini İslam müzik felsefesinde görürüz. Bir tarafta idealist-mistik bir kuram bir tarafta daha yaşamsal bir pratik ve deneyimsel bir sanat tecrübesi ön plana çıkmaktadır. İslam müzik felsefesinde El Kindi ve İbn-i Sina-Farabi geleneğinin harmanlanmasını en kuvvetli şekilde tasavvufta görürüz. Tasavvuf geleneğinde müzik son derece saygın bir yere sahiptir. "Sema" kelimesi düz anlamda dinleme demektir ve tasavvuf geleneğinde meditasyona benzer şekilde kalbi bir dinlemeye gönderme yapar. (Leaman, 2012:172) Diğer İslam uygulamalarından çok farklı bir konumda olan Tasavvuf geleneğinde müzik, "mikro-makro evren uyumunun" özel bir tınısı olarak görülmekte ve seslerle düşünmek, derin bir meditasyona yönelmek ve kainatın uyumunu, içimizde hissetmek amaciyla müzik, müzik olmanın dışında, Hegelci bir deyimle "kendinde ve kendisi için" bir varlık kategorisine çıkmaktadır.

İslam müzik geleneğinin ve Müslüman kuramcıların müziğe büyük bir katkısı olmuştur. Müslüman kuramcıların yaptığı en büyük katkı sesin küresel yayılımıyla ilgilidir. (Artz, 1980:146) $\mathrm{Bu}$ yayılım, beşliler armonisi ve seslerin, tonların dizinlenişini ifade eder. Bu temellendirme, batı tonalite dizilerinin ve beşliler armonisinin temelini oluşturmuştur. Bu noktada Batının, İslam'dan ödünç aldığı şeyler arasında şunlar vardır: "Ut, davul, başka müzik aletleri, şefin çubuğu ve kuramsal kuramsal akustik üzerine bir şeyler, ses uyumu için tellerin uzunluklarını ölçme düşüncesi ve belki de uyum ve ölçülü müzik düşüncesi vardır." (Artz, 1980:177)

\section{Genel Değerlendirme - Sonuç}

Çok geniş bir alana yayılan İslam estetiği ve sanat ontolojisinin etkisiyle gelişen sanat pratiklerinin dağılımını tek tek ele almak böylesi bir incelemenin kapsam alanını oldukça aşmaktadır. $\mathrm{Bu}$ incelemede temel amacımız, İslam sanat felsefesinin temel paradigmalarının oluşum sürecini ve bu süreçte ortaya çıkan temel estetik geleneğin arka planda var olan ontolojik kökenini anlama ve açıklamaya yönelmişti.

Bu noktada genel bir değerlendirme başlıklarını şöyle sıralayabiliriz:

İslam kültürünün en büyük ilerlemeler kat ettiği yüzyıllar 9. ile 12 yy. arasına denk gelir. ${ }^{14}$ $\mathrm{Bu}$ dönemde İslam kültürünün olağanüstü bir ilerleme gösterdiğini görürüz. 1065 'te Bağdat'ta büyük bir üniversite kuruldu. Bunu aralarında Şam, Kudüs, Kahire, İskenderiye ve Kordoba'daki önemli üniversiteler olmak üzere başka birçoğu izledi. Bă̆dat'ta 1234 yllında kurulan ikinci bir üniversite tümü arasindaki en büyüğ̈̈ oldu. (Artz, 1980:153) Fakat Müslüman uygarlık on birinci yüzyıldan başlayarak daha önce Roma İmparatorluğunun 5. yüzyılda karşılaştığı gibi daha aşağ kültürlerin denetimi altına girdi. Yalnızca Kuzey Afrika ve İspanya'da İslamik iklimin eski ışıkları henüz parlak olarak yanıyordu. Moğol etkisiyle çok az olan bu çalışmalar da yok edildi. (Artz, 1980:177)

İslam estetiğinin yüzü, nesnelere değil onların ötesine yönelmiş, matematiksel ve geometrik form aracılığıyla mükemmelliği aramıştır. Bu mükemmelliğin fikirsel olarak bu dünyada itici gücü kuşkusuz "cennettir". Yaşamsal ve estetik amaçlı yapılan bütün yüceltim kaynaklı idealist yaratıların temelinde bir şekilde "cennet fikri” bulunur. Bütün görsel sanat üretim

\footnotetext{
${ }^{14}$ İslam uygarlığı 8-13. yy. arasında olağanüstü bir ilerleme göstermiştir, bunu bilim ve felsefe dilindeki ilerlemeden ve batı dillerine geçen Arapça kökenli kavramların genişliğinde de görürüz. Arapçadan İngilizceye geçen bazı kavramlar şunlardır: "Chemistry, alcohol, alkali, alembic, elixir, nadir, zenith, cipher, zero, algebra, root, almanac, copula, camphor, orange, lemon, syrup, lute, guitar, coffee, lilac, sumach, jasmine, saffron, muslin, damask, satin, admiral, Arsenal, tariff, ginger, rice, cotton, artichoke, ream, sherbet, julep, candy, sofa." Artz,1980:177
} 
formlarında görülen bitkiler, aslında cenneti tasvir ederler. Çünkü: Kur'an'da cennetin işaretleri olarak değinilen bitkiler: hurma, nar, incir, üzüm, zeytin, tahillar ve çiçekler'dir. (Bahanassi, 2008:635) Bu öğeler İslam sanatlarının çoğunda imgesel olarak kullanılırlar. Cenneti temsil eden bu meyve, çiçek ya da tahıllar, ulaşılması güç bir idealin nesnelleşmesini temsil ederler. Bitki motifleri cenneti ve imanın mükafaatın temsil ederken daha soyut geometrik tasarımlar evrenin doğrudan bir ifadesi olarak kullanılmaktadır. (Bahanasi, 2008:637)

İslam düşüncesinde cennet fikri, estetik üretimde temelde iki etki yaratmıştır. Birincisi bu dünyaya yönelik ulaşılabilir bir ideal yaşam alanının tasarlanması, diğeri ise ölüm sonrası sadece hak eden müminlerin yaşayacağı seviyede en üst yaşam mekanına yönelik ideal mekanının imgesel tahayyülüdür. Birincisi: Cennet idealizasyonu ve bunun sanata sunduğu imgelem zenginliğiyle insan aklının sınırları zorlanır. İkincisinde ise cennet, bir ideal, ulaşılması hedeflenen bir yaşam mekanı olma yanında fikir olarak itici bir imgelem gücünü de temsil eder. Bu etki sadece temsil ya da imge olarak kullanılmaz. Estetik itici hamle ile "cennet" dünyevileşir. Bu dünyada cennetin inşa edilmesi ve bunun imkanı sorunu artık sanatçı, mimar, düşünür ve hatta devlet yöneticilerinin de görevi olur.

Dünyasal ihtiyaçlar bağlamında insanın en temel evrensel eylemi kuşkusuz "inşaa etmek ve barınmak" amaçlı yapılan eylemlerdir. Barınmak ve inşa eylemi, Heidegger'in de belirttiği gibi düşünmeyi, inşaayı ve iskan etmeyi; dörtlüyle bağlantılı olarak bir araya getirmektedir. (Heidegger, 1971:3) Bu dörtlü, aynı zamanda kutsal olanı da içerir. İnsanoğlunun inşa eylemlerinin çoğunun arka planında var olan itici bir güçtür cennet. Konutlar, kamusal bina ve meydanlar, kutsal mekanlar, bahçeler parklar bunlara örnektir. Bütün inşa eylemlerinin arkasında Heidegger'in de belirttiği gibi "Cennet-Heaven" fikir olarak belirleyicidir. Müslüman sanatında cennet fikri, ulaşılmaz olanı değil, ulaşılmaz olandan hareketle bu dünyada oluşabilecek güzel mekanlara dönüşür. Birisinde cennet, dünyadan kopuk öte dünyaya anlatan bir sanatsal ilke iken diğerinde bu dünyada nesnelleşecek olan bir düşünce yapısını görürüz.

İslam sanatında ikon ve temsil yasağı vardır. Fakat bu yasağın gerekçesi ontolojik ve epistemolojiktir. Hz. Muhammed kendisiyle ilgili tüm tanrısallığı yadsır (Artz, 1980:174) Hz. Muhammed, arkasında kendisinden sonra "kült nesnesi" olabilecek hiçbir şey bırakmak istemez. İslam, Hıristiyanlıktaki gibi görselleştirilebilir bir Tanrı, onun temsilcisi ya da suretine göndermede bulunmaz. İslam'da peygamber, siradan bir insandır ve ölümlüdür. İnsanüstü mucizeleri ya da güçleri yoktur. Bu yüzden İslam düşüncesinde Hz. Muhammed, Budizm ve Hiristiyanlığın düştüğü kültürel yanlışa düşmek istemediği için temsil yasağını getirir. Ondan yüzlerce yıl önce Budha, aynı durumun farkında olarak bunu yapmaya çalışmış fakat bunu başaramamıştır. Kült nesnelere tapınma ve ikonalaştırma eğilimlerini sert bir şekilde eleştiren Budha'nın düşünceleri değil, tam tersine, temsili ve ikonlaştırıcı bir din kavrayışı egemen olmuştur. Ayrıca Hırıstiyan üçlemesi ya da Arapların çok tanrılı dini geleneğine karşı olarak İslam düşüncesi tapınma nesneleri olmasın diye hiçbir insan, hayvan ya da bitki imgesinin kullanılmasina da izin vermemektedir. (Artz, 1980:172) $\mathrm{Bu}$ noktada Hz. Muhammed'in değerlendirmelerinin ontolojik bir temelde olduğunu ve kendi içinde haklı gerekçelere dayandığını görürüz. (Hamdouni, 2015:41)

Temsil ve ikon yasağı İslam geleneğinde sanatsal yaratımın sonunu mu getirmiştir? Kuşkusuz hayır, çünkü Hz. Muhammed'in, temsil ve ikon yasağı aslında Müslüman sanatçıyı düşünülenin aksine daha çok yaratıcı imgeleme zorlayacaktır. Hz. Muhammed'in ikon ve temsil yasağı dışında hiçbir yaratıcı sanatsal eyleme karşı çıtığını görmeyiz. Hz. Muhammed, kendisinin ileriye kalacak bir resim ya da temsilinin yapılmasına bu gerekçelerle yasak koymuştur. Ama inananlar, peygamberlerini merak ederler; bu merak kökensel olarak Aristotelesçi bir imgelemi zorlar ve aslında bu sınır yeni bir yaratıcı imgelemi teşvik eder. Böylece peygamber, bütün Müslümanların hayal gücünde bambaşka bir yüzle, formla, yeniden canlandırılan imgesel bir düşünce olarak sonsuz çeşitlilikte farklı beden ve renklerde yeniden var olur. Fakat şu da bir gerçektir ki zamanla bu yasaklamayla ilgili kapsam alanı genişletilmiş, "insan ve hayvan" 
imgelerinin kullanılması da aynı akıl yürütmeyle haksız bir şekilde yasaklanmıştır. Ontolojik bir temelde var olan bu sınırlandırma konuyla doğrudan ilişkisi olmayan sanatsal eylem ve üretime de engel olmuştur. (Artz, 1980:170) İslamı yaratanın, İslam sanatını ortaya çıkaranın da sanatsal ve hatta maddi bile değil, ama siyasal ve dinsel bir güç olduğunu hiçbir zaman akıldan çıkarmamalıyız. (Grabar, 2018:35) Bu gelişme sanatsal üretimi farklı yönde ilerlemeye mecbur bırakmıştır. Platoncu basit mimesis'in ötesine geçmeye zorlanan sanatçı, artık daha yaratıcı olmak durumundadır. Çünkü hem alımlayıcının hem de sanatçının gerçekliğe bakışı zorunlu olarak değişecektir. Sanat, artık bizi dış dünya gerçekliğinin ve maddelerin zahiri görünüşünü değil batini yönünü görmeye zorlar. Bu da onu zorunlu olarak Platon'un Timaios'ta belirttiği gibi daha soyut ve daha geometrik yapar.

İslam estetiğinde sanatçı kavramı daha başlangıçta sanatsal eser üretme sürecinin temelinde yer almaz. Batıdaki Cartezyen "özne-nesne" ayrımı genel olarak İslam estetiğinde karşımıza çıkmaz. "Ruh-beden, düşünce-madde" gibi dikatomik ayrımlara girmeyen erken dönem İslam düşüncesinde karşımıza varlığı ve doğayı, domine etmeyen bir estetik yaratım alanı çıkar. Bir yandan sonsuzluk tecrübesi diğer taraftan insanın fani dünyevi varoluşunun değersizliği bütün Müslümanlar tarafindan bilinir ve Müslüman sanatının bütün parçalarını bu bilinç oluşturur. (Leaman, 2012:34) Bütüncül bir evren kavrayışına sahip olan İslam düşüncesinde varlık ve doğadan kopuk, bağımsız bir "kadiri mutlak özne" modelinin gelişimini görmeyiz. Batı düşüncesinde meydana gelen Descartesçı epistemolojik devrimin, düalizmi, İslam dünyasında etki göstermez. Düşüncede meydana gelen ve "düşünceyi" bir varlık kategorisi olarak gören Cartezyen devrim, zorunlu olarak düalist bir karekter taşır. "Özne-nesne, ruh-beden" gibi ayrımlara bağlı gelişen gerçeklik ve kültür algısı, İslam dünyasında, Batıdaki gibi emperyal bir düşünceye, doğainsan ve emek sömürüsüne (kapitalizm) dönüşmez. Cartezyen düşünce, kapitalist (burjuva) temsili sanatın önünü açar ve aynı zamanda artık "immoral, ahistorik ve apolitik" bir kültüre geçiş de sağlanır. Sırasıyla din, aristoktrasi ve burjuva kontrolünde gelişen batı sanatının ilerleyişi zamansal ve diyalektik bir olgunlaşma süreci olarak okunur ve bu süreç zamanla, hükümdar gibi dominant bir sanatçı modeline dönüşür. Oysa İslam düşüncesinde böylesine bir ilerleme, olgunlaşma ve kadiri mutlak bir özne-sanatçı kavrayışına, İslam sanatının hiçbir döneminde rastlamayız.

Günümüzün en önemli kavramlarından birisi “insan hakları ve eşitliği” düşüncesi aslında İslam'ın özünde doğal olarak vardır. İslam dini, inananları her zaman eşit bir statüde değerlendirmiş hiçbir "aile, grup ya da sınıfa ayrıcalık verilmemiştir." Müslümanlarda "irksal, sosyal bir sınıfsal farklılık ya da üstünlük" fikri de yoktur, bütün "insanlar-inanalar kardeş, herkes eşittir. (Artz, 1980:134) Toplumsalcı ve devrimci bir temele sahip olan Müslümanlığın genel çerçevesinde bütün inananların eşitliği fikri, sosyal-siyasal ve estetik bilince de sirayet etmiş ve sanat alanında temsil ya da statü göstergesi olacak olan herhangi bir sınıfi yücelten göstergeler, estetik üretimin içine girememiştir.

Batı sanatında sanatsal yaratım ve sanata kurallar koyan sanatçının evrensel bir "tin" "geist" olduğu düşüncesi Kant ile gündeme gelmiş, Hegelci diyalektiğin ilerlemesi sonucu çeşitli evrelerden geçerek en sonunda yabancılaşmayı aşarak kendi bilincine ulaşmış fakat tam bu noktada, kendi "ölüme yazgılılığıyla" karşılaşmıştır. Ayrıca batı sanatında yaşanan Kantçı estetik dönüşüm İslam estetiğinde gerçekleşememiştir. Bunun temel nedenlerini şöyle sıralayabiliriz:

1- İslam estetik geleneğinde merkezi bir "sanatçı-özne" dominantllğı yoktur. Sanatçı, yaratıcı bir "Deha" değildir bu yüzden, İslam estetik geleneğinde Dehalar karşımıza çıkmazlar.

2- İslam estetiğinde "sanat-zanaat" ayrımı gerçekleşmez. Bu kavramlar hep koşut düşünülür. Çünkü güzel sanatların, zanaatten uzaklaşıp, yarar gözetilmeden üretilmesi düşüncesine İslam düşüncesinde yer verilmez.

3- son olarak: Kant'ın, batı sanatında gerçekleştirdiği önemli bir diğer gelişme sanatta Platon'dan beri var olan "iyi-güzel" sentezini ayırmak olmuştur. Fakat bu etik fonksiyondan 
uzaklaştırılmış estetik üretim düşüncesine İslam dünyası olumlu bakmaz, bakamaz. Sanatı, etik fonksiyondan uzaklaştırmak, İslam estetiğinde mümkün değildir; çünkü İslam sanatı, daha başlangıçta İslam dinine koşut ve öncelikli olarak etik ve araçsal bir işleve sahip olarak konumlandırılmıştır.

Ayrıca, İslam geleneğinde sanatçı, Sokratik bir tavırla "kendini tanıma" ve aynı zamanda bu yaşamındaki "yitimlilik" bilincini alımlayıcılara aktarmayı amaçlamaktadır. Böylece tikel sanat formları aracılığıyla sanat, "kötü konuşulan bir dil ya da dil öncesi bir yeti" (Hegel'e karşıt) olmanın ötesine geçmiş ve pozitif diyalektiğe karşı, çelişkinin varlığını koruyan, tikel ve sonlu sanatsal eylem ve yaratılarıyla negatif diyalektik bir yapıya dönüşebilmiştir. ${ }^{15}$ İslam estetiğinde, sanat eserlerinin salt estetik kaygılarla değil, estetik dışında "Íslam dini çerçevesinde" işlevsel bir amaca odaklandıklarını görürüz. Bu işlev, metafizik bir temelden gelen ve felsefi bir arka plana dayanan, kavramsal bir çerçevede belirlenmiş olmasına rağmen aynı zamanda seküler ürünler de verebilmiştir. İslam estetik geleneğinde, Hegelci bir estetik öz farkındalık, Kantçı bir etik-estetik ayrımı ve estetiğin kendine özgü "öz-bilinci” gelişemediği için estetik alanı, ideolojik bir zeminde sıkışıp kalmıştır. Her ne kadar seküler-dünyasallaşmış bazı üretim pratiklerine sahip olsa da İslam estetik üretim doktrini, temelde din merkezli-estetize edilmiş bir din- olmuştur. Bu gelişme İ̀lam sanatının yaşamdan uzak olduğu anlamına kuşkusuz gelmez. İslam estetik alanı, batıdaki gibi "episteme-ontolojik" bir dönüşümü epistemik ve estetik dönemsellik açısından geçirmemiştir. Ayrıca batı sanatında var olan "deha sanatçı, aristokrasi ya da burjuva"16 kontrolüne girmediği için de günümüzde, "kültür endüstrisi" sürecinin kıskacından kurtulabilmiş ender estetik alanlardan birisi olmuştur. Günümüzde Batıda ve diğer coğrafyalarda İslam estetiği ve Tasavvufa karşı gelişen entelektüel ve sanatsal ilginin nedenini burada aramak gerekir. Bütün bunların sonucu olarak batı ve diğer estetik görünümlerden farklı olarak İslam estetiği, diğer kültürlerin karşılaşmış olduğu "teknolojik ve sosyo-ekonomik" etkenlere karşı varlığını koruyabilmiş ve kendi otantikliği içinde, kendi estetik ilkeselliğini sürdürebilen "kendinde ve kendisi için" üretim yapabilen ancak, kendi özerk estetik ilkeleriyle "hermeneutik ve fenomenolojik" olarak anlaşlabilecek bir sanat pratiği olarak kalabilmiştir. ${ }^{17}$

Sonuç olarak İslam estetiğinde sanatçının, alımlayıcıdan radikal bir beklentisi olduğunu görürüz. Bu beklenti, temelde eksik ve yitimli olan insan varlığının, değişim karşısında değişmeyen doğasını anlamak amacıyla, temelde yitimli olan "zahiri" dünyanın illüzyonlarından kurtulma talebidir. İnananların, varlı̆̆ın batini olan yüzünü kavrayabilmesi için estetik üretimler, hem fenomenolojik-hermeneutik hem de tikel ve yaşanmışlık bağlamında egzistansiyel olarak üretilir ve ancak anlaş1labilirler. Tikel ve sonlu üretim modelleri olan bu sanat eserlerinin, bir bilinçlenme modeline dönüşebilmesi için onların fenomenolojik ve hermeneutik olarak analizinin yapılması zorunluğu karşımıza çıkmıştır. Bu amaçla da bu incelemede, doğrudan İslam estetiğinin kendisini oluşturan ilkeler ve belirlenimlerin analizi yapılmak istenmiştir. İslam estetiği denemesi sınırlarını hayli zorlayan bu çalışmada amacımız, bu sınırları ve kavramları tayin etmeyi amaçlamış ve bundan sonra yapılacak olan daha ayrıntılı tikel sanatsal yapılar üzerine eğilen estetik incelemelerin yapılması zorunluluğunu bir kez daha gün yüzüne çıkartmıştır.

\footnotetext{
${ }^{15}$ Bu noktada Adorno'nun "olumsuzlayıcı diyalektiğ $i ”$, sanat yapıtının "tikel yapısı” üzerine yaptığı değerlendirmeler, yapmış olduğumuz tespitlerle paralellik göstermektedir. Bu konuda ayrıntılı tartışma için bakınız, T.W. Adorno, Aesthetic Theory, (Transleted by Robert H. Kantor), USA: Minnesota University Press, 1998 Ayrıca bakınız, Susan Buck Morss, The Origin of Negative Dialectics, The Free Press, New York, 1979

${ }^{16} \mathrm{Bu}$ konuda Batı sanatının toplumsal tarihi üzerine ayrıntılı tartışma için bakınız, Hauser A., Sanatın Toplumsal Tarihi, Saray Sanatının Çöküşü, Almanya ve Aydınlanma.

${ }^{17} \mathrm{Bu}$ konuda ayrıntılı tartışma için bakınız, Moritz Geiger, Estetik Anlayış, Fenomenolojik Estetik, s.114- 128
} 


\section{Kaynakça}

Alamı, H. M. (2015). The Origins of Visual Culture in the Islamic World, Aesthetics Art, and Architecture in Early Islam. New Paperback Edition Published.

Adorno, T.W. (1998). Aesthetic Theory (Transleted by Robert H. Kantor). Minnesota University Press.

Adorno, T.W. (1972). Dialectic of Enlightenment (Translated by John Cumming). Continuum.

Aristoteles, (1996). Metafizik. (Çev. Ahmet Arslan). 2. Baskı, Sosyal Yayınları.

Aristoteles, (1998). Nikamakhos'a Etik.(Çev. Saffet Babür), Ayraç Yayınevi.

Aristoteles, (2007). Poetika. (Çev: İsmail Tunal1), Remzi Kitabevi.

Artz, F. B. (1980). The Mind of the Middle Ages. The University of Chicago Press.

Bahnassi, A. (2008). Sanat ve Estetikte Yaratıcllk. (Edit: E. İhsanoğlu) s.631-652, İslam Kültürü ve Bilgi, Cilt 5, Kültür ve Turizm Bakanlığı Yayınları.

Berger, J. (1995). Görme Biçimleri (Çev. Yurdanur Salman), İstanbul: Metis Yayıncıllk

Bernstein, J. M. (1992). The Fate of Art, Aesthetic Alienation from Kant to Derrida and Adorno, Polity Press, Cambridge.

Burke, S. (1998). The Death and Return of the Author, Edinburg University Press, Second Edition.

Collingwood, R.G. (1967). The Principles of Art. Oxford University Press.

Çam, N. (1999). İslam'da Sanat Sanat'ta İslam, 3. Baskı, Akçağ Basın Yayın.

Gasset J. O. (2013) Sanatın İnsansızlaştırılması ve Roman Üstüne Düşünceler, (Çev. Neyyire Gül Iş1k), YKY.

Grabar, O. (2018). İslam Sanatının Oluşumu, (Çev. Nuran Yavuz). Alfa Yayınları.

Grube, E. (1967). The World of Islam, McGraw-Hill.

Grobe, E. (1987). What is Islamic Architecture? Architecture of the Islamic World, G. Michell (ed) Thames\&Hudson.

Grabar, O., Ettinghaousen Elizabeth, and M. Jenkins Madina, (2001). The Art of Architecture of Islam 650-1250, Penguin Boks Ltd.

Grabar, O. (1973). The Formation of Islamic Art, Yale University Press.

Geiger, M. (2015). Estetik Anlayış (Çev. Tomris Mengüşoğlu), Doğu Batı Yayınları.

Hauser, A. (2006). Sanatın Toplumsal Tarihi, (Çev. Yıldız Gölönü) Deniz Yayınları.

Hegel, G. W. F. (1994). Estetik. (Çev. Taylan Altuğ \& Hakkı Hünler), Payel Yayınevi.

Heidegger, M. (1971). Building, Dwelling, Thinking by from Poetry, Language, Thought. (Translated by Albert Hofstadter), Harper Colophon Books.

Leaman, O. (2012). İslam Estetiğine Giriş, (Çev. Nuh Yılmaz) Küre yayınları.

Mehdi A.S. (2008). İslam Kültüründe Müzik. (Edit: E. İhsanoğlu) s.-819-834 İslam Kültürü ve Bilgi, Cilt 5, Kültür ve Turizm Bakanlı̆̆ı Yayınları.

Michon, L. J. (2008). İslam El Sanatlart, (Edit: E. İhsanoğlu) s.-893-916 İslam Kültürü ve Bilgi, Cilt 5, Kültür ve Turizm Bakanlığı Yayınları. 
Nietzsche, F.W. (1995). The Birth of Tragedy (Transleted by C.P. Fadiman). London Dover Publication.

Platon. (2001). Timaios (Çev. Erol Güney, Lütfi Ay). Sosyal Yayınları.

Platon. (2005). Devlet. (Çev. Sebahaddin Eyyüboğlu)- M. Ali Cimcöz) 9. Baskı, Türkiye İş Bankası Yayınları.

Platon. (2000). Şölen. (Çev. Cenap Kaya) Sosyal Yayınları.

Platon. (1998). Philebos. (Çev. Esat Siyavuşgil). Yeni Gün Haber Ajansı Yayınları.

Ross, D. (2002). Aristoteles. (Çev. Ahmet Arslan) Kabalcı Yayınevi.

Said, E. (2016). Kültür ve Emperyalizm. (Çev. Necmiye Alpay) Hil Yayınları.

Settar, H. (1955). İslam Mimarisi. (Çev. Nermin Sinemoğlu) Ankara Üniversitesi İlahiyat

Fakültesi Dergisi, s.68-74.

Schimmel, A. (1982). Tasavvufun Boyutları, (Çev. Yaşar Keçeci) Adam Yayıncılık.

Schimmel, A. (1984). Calligraphy and Islamic Culture, New York University Press.

Strauss, C. L. (2012). Yapısal Antropoloji,(Çev. Adnan Kahiloğulları) İmge Yayınları.

Whitehead, A. N. (1975). Science and Modern World. Fortuna Books, Cambridge University Press. 